\title{
Sexual selection by female choice prevents speciation reversal in a hybridizing trio of mormyrid fish in southern Africa: evidence from playback experiments of electric organ discharges
}

\author{
Daniela Schmid and Leo Bernd Kramer* \\ Zoological Institute of the University of Regensburg, \\ Universitätsstraße 31, 93040 Regensburg, Germany \\ *Corresponding author's e-mail address: bernd.kramer@ur.de
}

Accepted 6 May 2014; published online ???

\begin{abstract}
We studied the question of whether or not female choice among variant forms of species-specific male advertising signals, electric organ discharges (EODs), is a factor in preventing panmixy in a parapatric sibling complex of three species of mormyrid fish, inhabiting three parallel rivers in southern Africa. The three species' EODs are characteristically differentiated in waveform. The Upper Zambezi River is inhabited by Pollimyrus marianne Kramer, van der Bank, Flint, SauerGürth \& Wink, 2003, the Okavango River by P. castelnaui (Boulenger, 1911), and the smaller Kwando River in their middle by P. cuandoensis Kramer, van der Bank \& Wink, 2013, which is their hybrid species of unidirectional origin. $P$. castelnaui females $(N=4$ out of 5$)$ and $P$. marianne females $(N=5$ of 5$)$ responded stronger to playback of the EODs of male conspecifics compared to those of male P. cuandoensis. Pollimyrus castelnaui and P. marianne females neither preferred nor discriminated against the male EODs of each other's species, respectively (one exception). The single $P$. cuandoensis female available preferred a $P$. marianne male EOD over one of its own species, and was neutral in all other tests. This suggests that female resistance in the two main system species to $P$. cuandoensis male EODs is an evolved one, effectively limiting hybridization to the Kwando. The females of the two main system species, P. castelnaui and P. marianne, thus prevent panmixy in the Okavango and the Zambezi, respectively, thereby keeping up the threesibling species complex by discriminating female choice against $P$. cuandoensis males in the Okavango-Kwando-Zambezi system.
\end{abstract}

\section{Keywords}

assortative mating, choosy females, electrical communication, male advertisement signals.

\section{Zusammenfassung}

Verhindert elektrosensorische Paarungssiebung Panmixie in einem parapatrischen Drillingsartenkomplex von Nilhechten (Mormyridae) im südlichen Afrika durch Weibchenwahl? Die elektri- 
schen Organentladungen (EOD) der drei Arten sind artcharakteristisch verschieden. Pollimyrus marianne Kramer, van der Bank, Flint, Sauer-Gürth \& Wink, 2003 ist im Oberen Sambesi beheimatet, P. castelnaui (Boulenger, 1911) im Okavango, und P. cuandoensis Kramer, van der Bank \& Wink, 2013 in der Kontaktzone im dazwischen und parallel zu den beiden anderen verlaufenden, kleineren Kwando-Fluß. Die letztere Art entstand durch natürliche, unidirektionale Hybridisierung aus den beiden anderen. In Wahlversuchen konnten Weibchen aller drei Arten zwischen einer vorgespielten arteigenen und einer artfremden männlichen EOD wählen. Sowohl $P$. castelnaui- $(N=4$ von 5) wie alle $P$. marianne-Weibchen $(N=5)$ beantworteten arteigene Männchen-Signale stärker als solche von $P$. cuandoensis. Weder bevorzugten $P$. castelnaui- und $P$. marianne-Weibchen die EODs ihrer gegenseitigen Männchen noch lehnten sie sie ab (eine Ausnahme). Das einzige $P$. cuandoensis-Weibchen reagierte stärker auf $P$. marianne-EODs als auf jede von 6 arteigenen und zeigte keine sonstigen Präferenzen. Gegen die EODs von $P$. cuandoensis-Männchen diskriminiende Weibchen der beiden anderen Arten sind offenbar ein Ergebnis der Stammesgeschichte. Letztere verhindern somit im Okavango und im Sambesi Panmixie und damit die Umkehr der Artdifferenzierung von P. marianne aus P. castelnaui, der basalen Art. Elektrosensorische Paarungssiebung durch Weibchenwahl trägt dazu bei, das Trio von Pollimyrus-Arten im OkavangoKwando-Sambesi-System aufrecht zu erhalten.

\section{Introduction}

The nocturnal freshwater fish family Mormyridae is endemic to Africa, and well-known for their elaborate electro-communication and -location abilities. These fishes' electric organ discharges (EODs) are usually short pulses (approx. $1 \mathrm{~ms}$ ) of widely varying waveform among species. The waveform is the species-characteristic fixed part of an individual's means of communicating with conspecifics, whereas the pulse rate is context-dependent and reflects an individual's state of excitation (Lissmann, 1958; Bennett, 1971a, b; Szabo, 1974; Szabo \& Fessard, 1974; for reviews, see Kramer, 1990, 1996, 2009; Moller, 1995; Bullock et al., 2005; Hopkins, 2009).

In previous studies species-characteristic sequences of inter-discharge intervals (IDI) have been identified in several mormyrid species, and experimental subjects usually showed a preference of their own species' patterns in playback experiments (Kramer \& Lücker, 1990; Kramer \& Kuhn, 1994). However, these species pairings using commercially acquired specimens did not include closest relatives and, therefore, the question of whether or not differentiation of IDI patterns was driving speciation remained unresolved. Other studies examining speciation in close mormyrid relatives include those of Arnegard et al. (2005) (focussing on EOD waveform polymorphism in Brienomyrus species) and Arnegard et al. (2006, 2010) and Gallant et al. (2011), the latter focussing on electric organ morphology. Arnegard et al. 
(2006) focussed EOD features coded by knollenorgan electroreceptor organs, and Arnegard et al. (2010) on ecological divergence.

In most vertebrates, choosy females select superior males for mating, and male advertising signals may be among the clues mormyrid females utilise to maximise their reproductive success (similar to other animals, Andersson, 1994; Andersson \& Simmons, 2006). Daytime male advertising by IDI pattern has been identified in Marcusenius altisambesi (Machnik \& Kramer, 2011), and sexual selection based on male EOD waveform clues, studied during the nocturnal activity period, has been demonstrated experimentally in two allopatric species of southern Africa, Marcusenius altisambesi (Machnik et al., 2010) and M. pongolensis (Machnik \& Kramer, 2008a) (Hanika \& Kramer, 2005, 2008).

As a next step a pair of true sibling species indistinguishable to the untrained eye, but clear morphological, genetic and EOD waveform differentiation were tested. These were the two vicariant dwarf stonebasher species of the Okavango, Pollimyrus castelnaui Boulenger (1911), and of the Upper Zambezi, Pollimyrus marianne Kramer, van der Bank, Flint, Sauer-Gürth \& Wink, 2003. An extended period of study did not reveal any speciescharacteristic IDI patterns, not even during courtship and breeding cycles in the laboratory. In playback experiments the experimental subjects did not show any preference for one or the other species' IDI patterns. These experiments aimed at detecting hypothetical species-specific features hidden to the human observer but potentially recognised by the experimental subjects, and were not found (Baier \& Kramer, 2007).

By contrast, in another series of experiments focussing on the speciesspecific EOD waveforms, all four $P$. marianne experimental subjects and two out of eight $P$. castelnaui subjects preferred to associate with the signal source playing back conspecific EODs for a significantly longer time, and not a single subject preferred the alternative signal, the EOD of the other species. In these studies both species' EOD waveforms were played back simultaneously in an unforced choice paradigm (Markowski et al., 2008). The low proportion of discriminating $P$. castelnaui experimental subjects, compared with the $100 \%$ response of the $P$. marianne subjects, may be related with the observation that $P$. castelnaui's EOD waveform presents several cryptic differences between the sexes. In addition, the experimental subjects in both species were of both sexes, as were also the specimens chosen for recording 
playback stimulus EODs. Similar intraspecific variability but no sex differences had been observed in P. marianne's EOD waveform (Markowski et al., 2008). Acute discrimination of individuals within the intraspecific EOD waveform variation has been demonstrated in trained, food-rewarded Pollimyrus adspersus and Gnathonemus petersii (Graff \& Kramer, 1992; Paintner \& Kramer, 2003).

There is a third, closely related Pollimyrus species in the Kwando River, Pollimyrus cuandoensis Kramer, van der Bank \& Wink, 2013, which combines some of the characteristics of both neighbouring species (Kramer et al., 2013). The Kwando River is running in parallel to and in-between the two major systems of the Okavango and Zambezi at almost equal distance. The lower Kwando is sporadically connected with, and sometimes flooded by, one or two of the major river systems on either side. Pollimyrus cuandoensis used to be considered a form of $P$. marianne within the intraspecific variability, because DNA sequence analysis of the cyt- $b$ gene did not show sufficient differentiation in spite of morphological, EOD, and geographic differentiation. It has since been recognised as a hybrid species of an intermediate phenotype, and P. marianne as the mother species and P. castelnaui the father species. We here use the rare chance to study three parapatric and partially overlapping species of southern Africa that are linked by a hybridization zone. Using playback experiments, we aim to find out whether or not sexual selection in the form of female choice may have given rise to and/or is keeping up this three-species complex, given that there is ample potential and opportunity for interbreeding and hybridization in the lower Kwando contact zone.

\section{Material and methods}

\subsection{Fish}

Pollimyrus marianne Kramer, van der Bank, Flint, Sauer-Gürth \& Wink, 2003 were caught at Namibia: Caprivi Strip: Upper Zambezi River: Lisikili side channel, $17^{\circ} 29^{\prime} \mathrm{S}, 24^{\circ} 26^{\prime} \mathrm{E}$, on 22 August 1999, by F.H. van der Bank and B. Kramer (for geography, see Figure 1). The fish were transported live to the aquaria of Johannesburg University by road where they were kept for a few days. By an overnight flight (1-2 September 1999) via Frankfurt they were transported to Regensburg University. Similar treatment was given to 


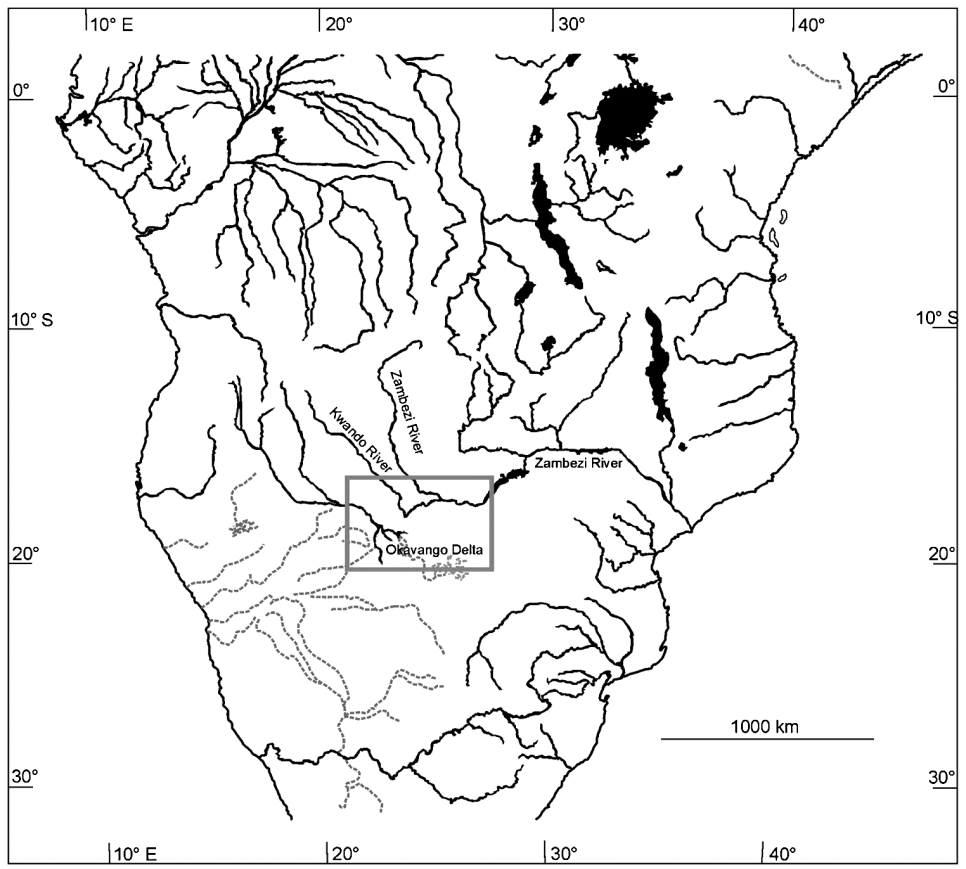

(A)

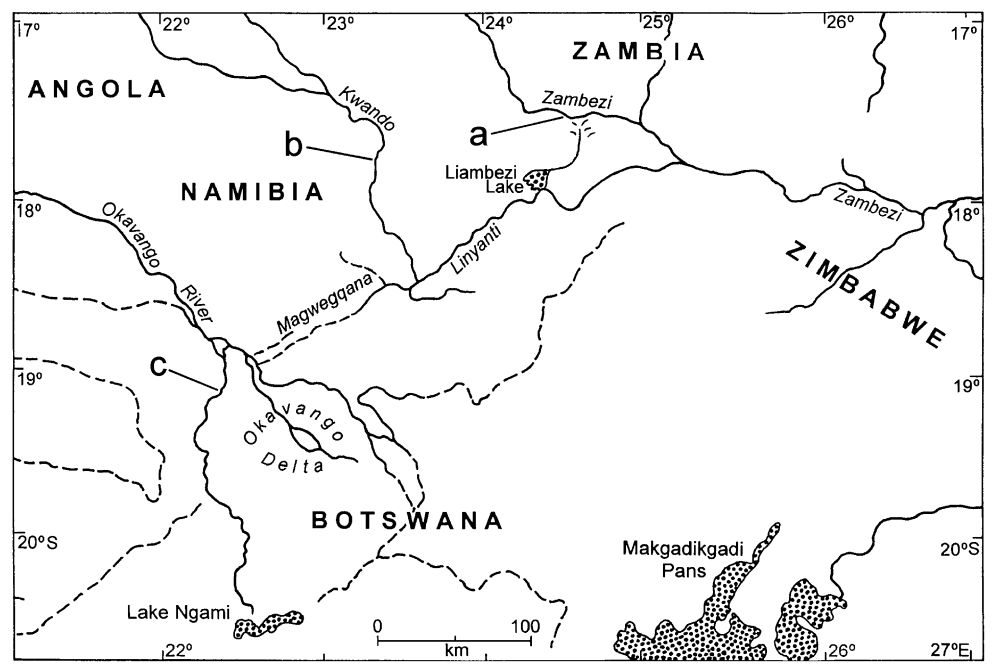

(B)

Figure 1. (A) Southern Africa, with study area in frame. (B) Sampling localities for the three Pollimyrus species: (a) the Upper Zambezi at Lisikili for P. marianne, (b) the Kwando River at Kongola Bridge for P. cuandoensis, (c) the Okavango Delta at Makwena for P. castelnaui. 
Pollimyrus castelnaui (Boulenger, 1911) caught at the Okavango panhandle region: Makwena, $19^{\circ} 03^{\prime} 16.2^{\prime \prime} \mathrm{S}, 22^{\circ} 22^{\prime} 51.3^{\prime \prime} \mathrm{E}$, caught by F.H. van der Bank in March 2002, arrival 22 March 2002 in Frankfurt and Regensburg. Both species bred successfully in the laboratory for several times. No interbreeding was attempted and the fish kept separately in different tanks. Two $P$. marianne individuals and three $P$. castelnaui individuals had been raised in the laboratory (first generation).

Pollimyrus cuandoensis Kramer, van der Bank \& Wink, 2013 specimens were caught at Namibia: Caprivi Strip: Kwando River: Kongola Bridge, $17^{\circ} 47^{\prime} 33^{\prime \prime}$ S, $23^{\circ} 20^{\prime} 33^{\prime \prime} \mathrm{E}$, on 8 August 2004, by F.H. van der Bank and B. Kramer. EOD recordings of all 42 specimens were made in the field after capture, and their standard length determined. A male and a female were transported live to the aquaria of Johannesburg University by road where they were kept for a few days. By an overnight flight via Frankfurt (18/19 August 2004) they were transported to Regensburg University.

All fish were big enough for sexual maturity to occur. The males of all three species carry a characteristic 'kink' at the base of the anal fin whereas it is almost straight in females (Kramer et al., 2003). The maximum size is $7.1 \mathrm{~cm}$ and rarely observed.

\subsection{Electric organ discharges}

In the present study the experimental subjects were female $(\mathrm{SL} \geqslant 5.6 \mathrm{~cm})$, whereas we recorded the EODs of males $(\mathrm{SL} \geqslant 5.0 \mathrm{~cm})$ for playback stimulation only. Their EOD pulse waveforms are shown in Figure 2. Pollimyrus marianne samples exhibit a simple triphasic waveform: head-positive, headnegative, head-positive that is distinct from their sibling species', P. castelnaui, pentaphasic waveform with a terminal $\mathrm{P}$ phase that is the strongest head-positive phase (Kramer et al., 2003; Markowski et al., 2008). The EOD of $P$. cuandoensis is highly variable among specimens, and combines features of the other two species in a way found in neither: a pentaphasic waveform, a $P$. castelnaui feature, goes together with a terminal $\mathrm{P}$ phase that is not the strongest positive phase, as seen in P. marianne.

Two isolated males per species, that is, six in all, were chosen to record their night-time inter-discharge interval (IDI) pattern when patrolling their aquarium at a moderate mean discharge rate $(24.2$ to $27.9 \mathrm{~Hz}$; Figure 3, only one male per species shown). IDI patterns recorded during this behavioural state were found to be 'neutral' and not openly repellent to conspecifics 


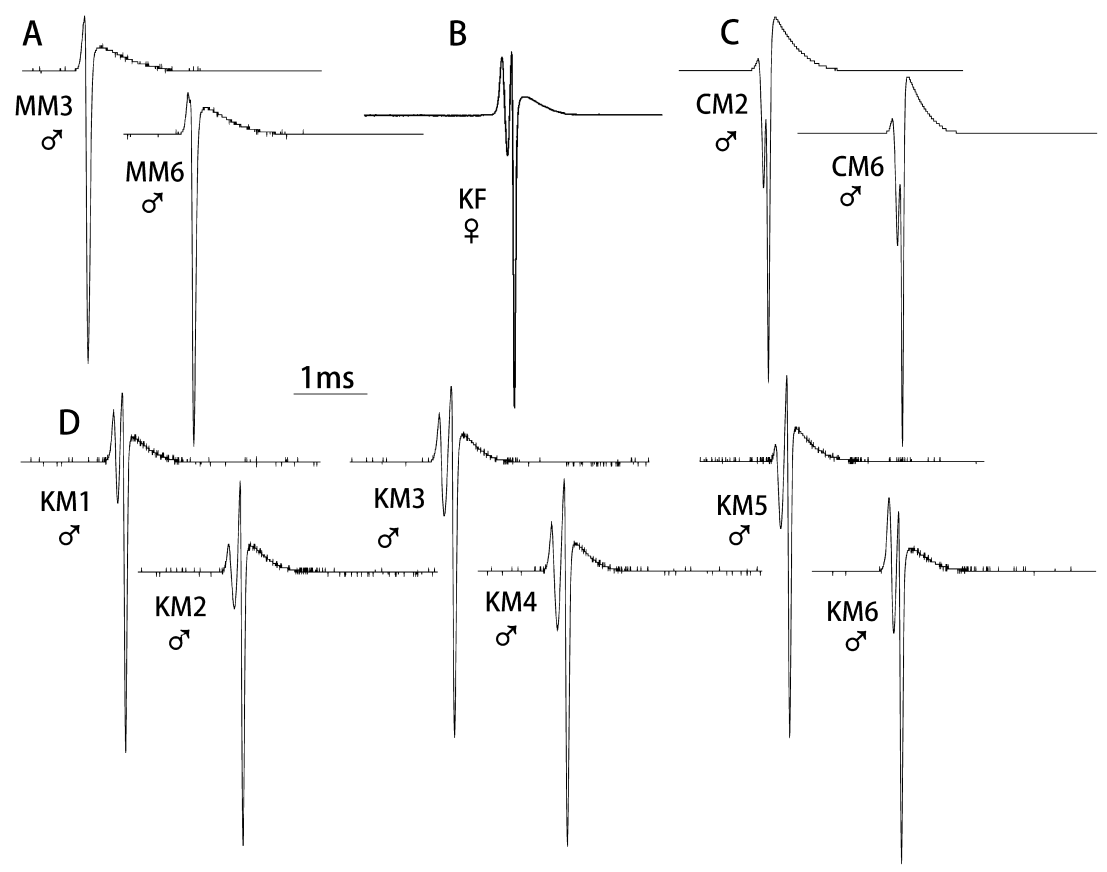

Figure 2. Electric organ discharges (EODs) of three Pollimyrus species of the Upper Zambezi/Kwando/Okavango system. Ordinate, relative amplitude, baseline equal to zero V. Headpositivity upwards. Abscissa, time as indicated by time bar. (A) Pollimyrus marianne, male MM3 of standard length (SL) $6.7 \mathrm{~cm}$, male MM6 of SL $6.3 \mathrm{~cm}$. (B) female P. cuandoensis, experimental subject KF of SL $6.0 \mathrm{~cm}$. (C) P. castelnaui, male CM2 of SL $5.2 \mathrm{~cm}$, male CM6 of $5.9 \mathrm{~cm}$. (D) P. cuandoensis, males KM1 of SL $5.1 \mathrm{~cm}, \mathrm{KM} 2$ and KM3 of $5.2 \mathrm{~cm}, \mathrm{KM} 4$ of $5.3 \mathrm{~cm}$, KM5 of $5.4 \mathrm{~cm}$, and KM6 of $5.0 \mathrm{~cm}$. All EODs except (B) used as stimulus EODs in playback tests.

(Machnik \& Kramer, 2008b). The IDI patterns were similar in the three species, and were used to drive the presentation of playback EODs of their own species, respectively. IDI intervals ranged from about 15 to about $95 \mathrm{~ms}$ with a single mode of about $30-50 \mathrm{~ms}$. A second male's pattern was used to guard against the possibility of one male's pattern being especially attractive or repellent. Both patterns were used equally often but turns were randomized.

\subsection{Test aquarium}

An experimental female was offered a porous pot for hiding in the middle of a test aquarium of $3 \mathrm{~m}$ length, $0.7 \mathrm{~m}$ width, and $0.6 \mathrm{~m}$ height, with the pot facing the long side of the aquarium (Figure 4). We placed two stimulus 

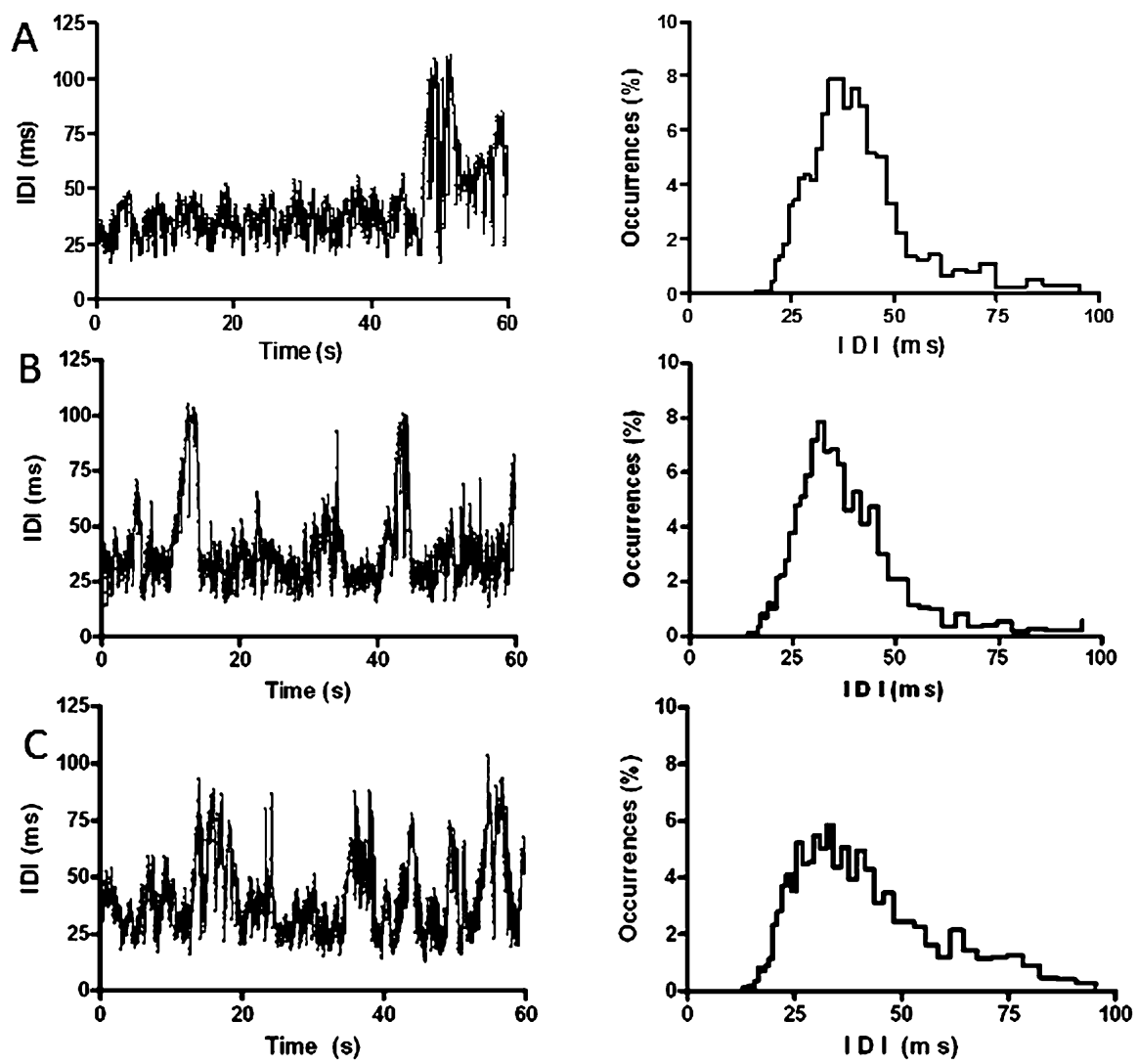

Figure 3. Inter-discharge interval (IDI) patterns recorded from isolated males when slowly patrolling their aquarium at night. Left panels, the sequence of IDI intervals over time. Right panels, histograms of the IDI patterns to their left, with relative occurrences (in percent of total) on the ordinate, and IDI length in ms on the abscissa. (A) Pollimyrus marianne, male MM1, mean discharge rate, $26.52 \mathrm{~Hz}$. (B) Pollimyrus cuandoensis, male KM2, mean discharge rate $28.78 \mathrm{~Hz}$. (C) Pollimyrus castelnaui, male CM2, mean discharge rate $27.92 \mathrm{~Hz}$.

dipoles in parallel to and symmetrically to the pot at $0.3 \mathrm{~m}$ distance each to its right and left. The dipoles consisted of two short, vertical carbon rods of $1 \mathrm{~cm}$ length and $0.5 \mathrm{~cm}$ diameter (separated by $2.5 \mathrm{~cm}$ ) mounted on a short piece of plastic tubing fixed to the aquarium floor by suckers. Centred on and parallel to the dipoles, the area delimited by parallel, straight lines separated by $20 \mathrm{~cm}$ was defined as the area 'close to dipole' that was entered by an experimental subject when it showed interest in the playback signal. 


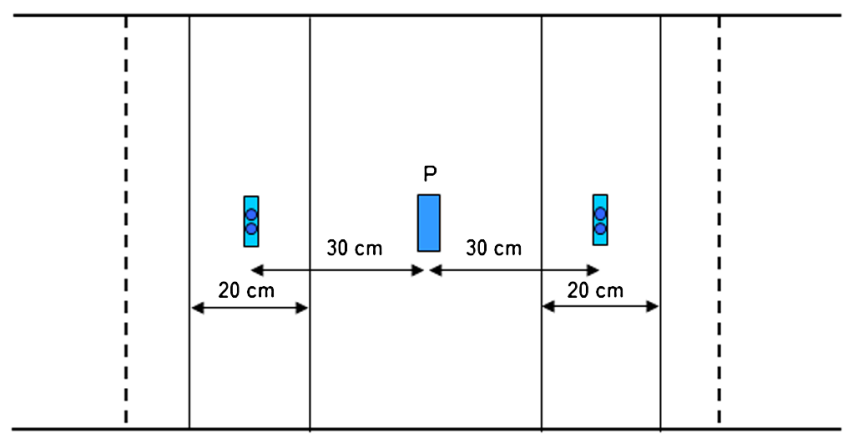

Figure 4. Top view of central area of the test aquarium of $3 \mathrm{~m}$ length, $0.7 \mathrm{~m}$ width and $0.6 \mathrm{~m}$ height. The range accessible for the experimental subject was reduced to $1 \mathrm{~m}$ length by plastic mosquito screen walls (hatched). An experimental subject hiding in porous pot $\mathrm{P}$ was played back EODs generated by two dipoles, one on either side, at $30 \mathrm{~cm}$ distance each from the pot (centre to centre). An experimental subject showed interest in a playback signal when it entered an area $20 \mathrm{~cm}$ wide centred on one of the dipoles. This figure is published in colour in the online edition of this journal, which can be accessed via http://booksandjournals. brillonline.com/content/journals/1568539x.

Two plastic mosquito screen walls closed off the experimental area of $1 \mathrm{~m}$ length from the rest of the aquarium such that the fish accepted the porous pot for shelter in the pre-test time of two days and did not escape during tests.

\subsection{Electronic setup}

The two dipoles that generated the playback EODs in the test aquarium were independently driven by one DAM unit each (Figure 5). A DAM is a microprocessor-controlled digital-to-analogue converter with memory (Electronics Workshop Biology, University of Regensburg; Kramer \& Weymann, 1987). Its memory stored EOD waveforms and lists of IDI patterns in digital form. Its symmetrical, bipolar output circuit (that generated an analogue EOD waveform) was internally triggered by one of these lists. A personal computer (IBM compatible) downloaded EOD waveforms and IDI lists to the DAMs via digital interface. The PC also controlled onset and stop of DAM activity, output amplitude, and the combination of EOD waveform and IDI list (on E1 and E2, Figure 5).

Stimulus pulse waveform quality as recorded from the aquarium was monitored by the dashed line circuits in Figure 5. Two pairs of carbon rod electrodes, each in line with one dipole in its middle, were connected separately with two differential amplifiers (V1 and V2; Electronics Workshop Biology, 


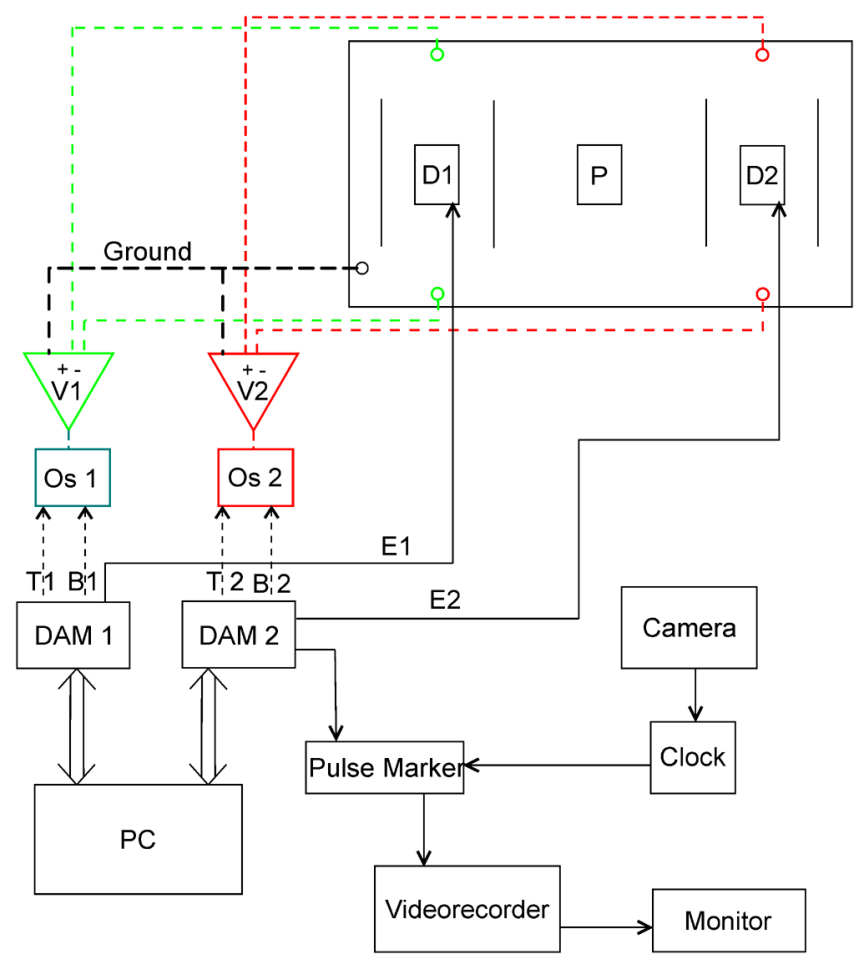

Figure 5. Electronic setup to test spontaneous preference for alternative EOD playback signals in Pollimyrus species. B1, B2, generator output to oscilloscope; DAM1, DAM2, EOD signal generators 1 and 2; D1, D2, dipole stimulators; E1, E2, leads connecting generator output with dipole stimulators; Os1, Os2, oscilloscopes 1 and 2; P, porous pot shelter for experimental subject; PC, personal computer; T1, T2, trigger signal for oscilloscope sweep; V1, V2, differential amplifiers 1 and $2(1-100000 \mathrm{~Hz})$. This figure is published in colour in the online edition of this journal, which can be accessed via http://booksandjournals.brillonline. com/content/journals/1568539x.

University of Regensburg) to display the playback EOD recorded from the water on an oscilloscope. The synchronous DAM output signal was also displayed on the oscilloscope screen on another channel. To this end, the EOD output trigger signals of each DAM (leads B1 and B2) triggered the sweeps of two oscilloscopes (Os1 and Os2), one for each dipole respectively, that displayed direct DAM output (via leads T1 and T2) and its representation as recorded back from the aquarium (via the dashed circuits leading to V1 and V2). No waveform distortion was detected in the playback EOD recorded from the aquarium in the present setup. 
An infrared-sensitive video camera (Cohu model FK 6990 B-IQ; lens: Pentax Cosmicar 1.0: 8-48 mm) filmed the fishes' behaviour under infrared illumination with no visible light (cut-off $830 \mathrm{~nm}$, model UF 500 FL, Derwent Systems). A clock signal stored on a separate videotape channel and an EOD pulse marker signal (from both DAMs) added to the video signal aided in the off-line analysis of the SVHS video tapes (videorecorder model Panasonic AG 7350, Matsushita Electric). The observer controlled stimulus onset and watched the fish's behaviour on a video monitor hidden behind a black curtain for darkrooms.

\subsection{Stimulus amplitude}

A P. marianne male of maximum size (SL $7.1 \mathrm{~cm}$ ), centred in the test aquarium at point $\mathrm{P}$ (Figure 4), generated a peak-to-peak amplitude of $30 \mathrm{mV}$ across the aquarium, measured with carbon rod electrodes fixed at the walls of the aquarium (that was $70 \mathrm{~cm}$ wide), at $25.1^{\circ} \mathrm{C}$ and $64 \mu \mathrm{S} / \mathrm{cm}$. We adjusted DAM output amplitude to match this value under identical conditions, with the male replaced by a dipole stimulator.

An experimental subject at $\mathrm{P}$ in Figure 4 experienced a field strength of $500 \mu \mathrm{V} / \mathrm{cm}$ peak-to-peak generated by a dipole stimulator at a distance of $30 \mathrm{~cm}$. The measuring dipole consisted of a pair of parallel, vertically orientated glassy carbon rods (Sigradur G, HTW) of $1 \mathrm{~mm}$ diameter and $6 \mathrm{~cm}$ length that were separated by $1 \mathrm{~cm}$ (centre-to-centre; Mechanical Workshop Biology, University of Regensburg). The electrodes were insulated except for their tips of $3 \mathrm{~mm}$, and rotated to find the local maximum value.

\subsection{Procedure}

An experimental subject was allowed two days to acclimatize to the test aquarium of $25 \pm 0.2^{\circ} \mathrm{C}$ and $65 \pm 3 \mu \mathrm{S} / \mathrm{cm}$ water conductivity (both ranges), and a light/dark cycle of $13 / 11 \mathrm{~h}$, similar to their keep conditions and their subtropical habitat in local summer. Twelve to 13 playback tests per night started 10 min after dark. A playback test lasted for $60 \mathrm{~s}$, and 8 min of rest were allowed before the next test was started. Playback stimulation was only started with the experimental subject inside its shelter.

An experimental female subject was given the choice between two different male EODs, played back simultaneously by the two dipole stimulators on either side of its porous pot shelter, driven by different IDI patterns so that coincidence of pulses was avoided. Preference for one EOD was measured 
as the difference in association time (staying in the area defined as 'close' to a dipole stimulator), the frequency of head butts directed at the stimulators, and the number of circles performed around the stimulator. Head butts and circling are typical behaviours seen in courtship and spawning (Baier $\&$ Kramer, 2007). One of the two male EODs that were contrasted in a test was a conspecific one, of which there were two representations in order to guard against the possibility of one being immensely attractive or repulsive (Kroodsma, 1989). The two conspecific stimulus EODs were used equally often in a test series at a randomized sequence.

The other stimulus EOD was a heterospecific one. For example, for a $P$. marianne experimental subject of female sex, as for all other experimental subjects in the present study, the heterospecific EOD was either a male $P$. castelnaui EOD or a male P. cuandoensis EOD. For both $P$. marianne and $P$. castelnaui there were two stimulus EODs recorded from two males, but six $P$. cuandoensis stimulus EODs recorded from six males; six because of the greater EOD variability in $P$. cuandoensis. The two $P$. marianne and two $P$. castelnaui EODs were played back equally often in a randomized sequence (coded MM and CM in tables and figures). Furthermore, to guard against a left/right side preference, each EOD waveform was presented on both sides equally often, following a randomized sequence. Also randomized was the choice between two IDI patterns per species. This made 88 tests per experimental subject. Randomisation of permutations was achieved using Table 15.6 of Cochran \& Cox (1957). Once used a block was never used twice.

\subsection{Behavioural response criteria}

The behavioural response criteria measured after stimulus onset were: Association time, the time spent in the area defined as 'close to dipole' (Figure 4); circling, the number of full circles $\left(360^{\circ}\right)$ around an active dipole; head butt, the butting of an active dipole. Incomplete movements, such as stopping short of a dipole or head butting of the leads, were disregarded. Any behaviour after stimulation had stopped was also disregarded.

These behaviours were determined viewing the video recordings made during the stimulation tests.

\subsection{Statistics}

The null hypothesis was 'there is no difference in the response of a female experimental subject to the playback of conspecific compared to heterospe- 
cific male EODs'. Under this hypothesis female Pollimyrus castelnaui, $P$. marianne and P. cuandoensis would show similar behaviour towards playback EODs of males of any of these three species.

A female experimental subject showed her preference for a specific male EOD pulse by a greater frequency of head butts, circles, or longer association time than for the alternative playback EOD. Therefore, only score differences were entered in a paired $t$-test or its nonparametric equivalent, the Wilcoxon matched-pairs signed-ranks test, with $\alpha=0.05$. We did not detect any habituation. Fish were responding well also in the last test session of a series. Because of our paired experimental design, any hypothetical swings of mood were controlled for.

\section{Results}

\subsection{Attraction test of conspecific vs other conspecific male EODs}

Five female $P$. castelnaui of $\mathrm{SL} \geqslant 5.6 \mathrm{~cm}$ were played back two conspecific male EODs, CM2 and CM6 (Figure 2), in order to find out whether or not they discriminated between these, that is, showed differences in association time or the frequency of head butts (Figure 6). Head butts and circling (additionally tallied in the main tests) are commonly shown behaviours in interacting mates (Lamml \& Kramer, 2005, 2006; Baier \& Kramer, 2007). All subjects responded well to the playback stimulation by swimming towards and associating (successively) with both dipoles, and also head-butting it as if it were a fish, but only two subjects discriminated between the two conspecific playback pulses. Female CF1 displayed more head butts to playback
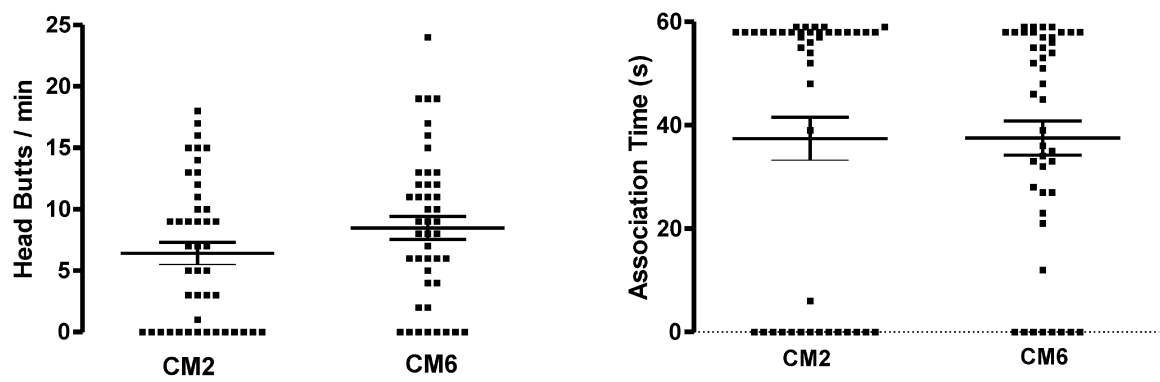

Figure 6. Mean response scores $\pm \mathrm{SE}$ of $P$. castelnaui female $\mathrm{CF} 2$ for right and left stimulus dipoles on stimulation with two conspecific male EODs, CM2 and CM6. Left panel, head butts per min; right panel, association time in $\mathrm{s}$. Full time spent at one dipole means zero time spent at the other. 
EOD CM2, whereas in female CF4 the EOD CM6 evoked more head butts (differences significant; Table 1). Since there was no clear group preference for one or the other conspecific male EOD, and no significant difference in association time in any of the subjects, the data for both conspecific stimulus EODs (that were used equally often in the main playback tests below at a randomized sequence) were combined.

We tested five $P$. marianne females (SL $\geqslant 6.2 \mathrm{~cm}$ ) in a similar way, using the pre-recorded EODs of two male $P$. marianne as playback pulses (code nos MM3 and MM6; Figure 2). Also these experimental subjects responded well to playback stimulation, leaving their shelter shortly after stimulus onset. None of the experimental subjects discriminated between the two stimulus pulses in the frequency of head butts; however, two subjects did regarding association time (Table 1). Experimental subjects MF3 and MF4 responded by a longer association time to pulse MM3 than MM6. Overall, however, pulse MM3 did not appear vastly more attractive than pulse MM6, and both were used equally often in the playback tests below at a randomised sequence, and results for both combined. The single $P$. cuandoensis female KF did not discriminate between MM3 and MM6, neither in association time nor in head butts (Table 1).

\subsection{Attraction tests of conspecific vs heterospecific male EODs}

\subsubsection{Pollimyrus castelnaui}

Five experimental subjects, all female $P$. castelnaui, were allowed to choose between a conspecific and a heterospecific male EOD in paired playback tests. A conspecific playback male EOD was contrasted with one out of six different $P$. cuandoensis male EODs, or a $P$. marianne male EOD. We tested six $P$. cuandoensis EODs because of their greater variability compared to the other two species' EODs.

Three experimental subjects showed a higher frequency of head butts to dipole stimulators playing back conspecific EODs than to certain heterospecific EODs (Figure 7A, Table 2). The reverse result - a stronger response to heterospecific EODs - was not observed. The experimental subjects discriminated against three (CF2) or four (CF1 and CF3) heterospecific EODs, among them $P$. marianne's EOD (MM for experimental subject CF2; Table 2). The data for CF4 and CF5 were almost all in the same direction but did not reach significant discrimination between any of the pulse pairings.

In this test the least attractive $P$. cuandoensis EODs were KM1 (relative avoidance in three experimental subjects), followed by KM5 and KM6 
(avoided by two subjects), followed by KM2, KM3, KM4 and MM (avoided by one subject each). Each heterospecific playback EOD was avoided by at least one experimental subject, whereas none avoided a conspecific playback EOD.

When the stimulus-evoked behaviour was measured as association time, also three experimental subjects showed significant, positive response differences (Figure 7B). Subjects CF1, CF3 and CF4 significantly preferred staying close to the 'conspecific' dipole stimulator for a longer time than the one playing back $P$. cuandoensis EODs KM1, KM2, KM4, or KM5 (Table 2). Again, none showed a preference for a heterospecific EOD.

The playback-evoked frequency of circling around the dipole stimulators was significantly greater for conspecific pulses than those for $P$. cuandoensis EODs KM2 and KM6 in subject CF1, and for KM5 in CF3 (Figure 7C, Table 2).

Females $\mathrm{CF} 1$ and $\mathrm{CF} 3$ showed discrimination in all three behavioural measures, whereas CF2 did so only for head butts and CF4 only for association time; female CF5 responded to the playback stimulation but without discriminating. Generalising over all experimental $P$. castelnaui subjects and all tests in the three behaviours measured, the least attractive $P$. cuandoensis EOD proved to be pulse KM5 (relative avoidance significant in five test series), followed by KM1 (four), then KM2 and KM6 (three each), KM4 (two), and KM3 and MM (one in both). The P. marianne EOD pulse was avoided in one test only (head butts in CF2), but otherwise neither discriminated against nor preferred.

\subsubsection{Pollimyrus marianne}

Five experimental subjects, all female $P$. marianne, were tested in a similar way to $P$. castelnaui. Here, one of two pre-recorded, conspecific $P$. marianne male EODs was played back simultaneously with one of six $P$. cuandoensis male EODs, or a P. castelnaui male EOD, and the response scores recorded. Four experimental subjects displayed significantly more head butts to a dipole stimulator playing back conspecific pulses than to certain heterospecific pulses. Subject MF1 showed relative avoidance to the $P$. cuandoensis-KM3 EOD, subject MF2 to KM5, and subjects MF4 and MF5 both to KM6 (Table 3). The P. castelnaui EOD (code CM) was neither preferred nor avoided by any of the subjects (Figure 8A).

Four experimental subjects were attracted to a dipole stimulator playing back conspecific pulses rather than certain other pulses for significantly 
D. Schmid, L.B. Kramer / Behaviour (2014)

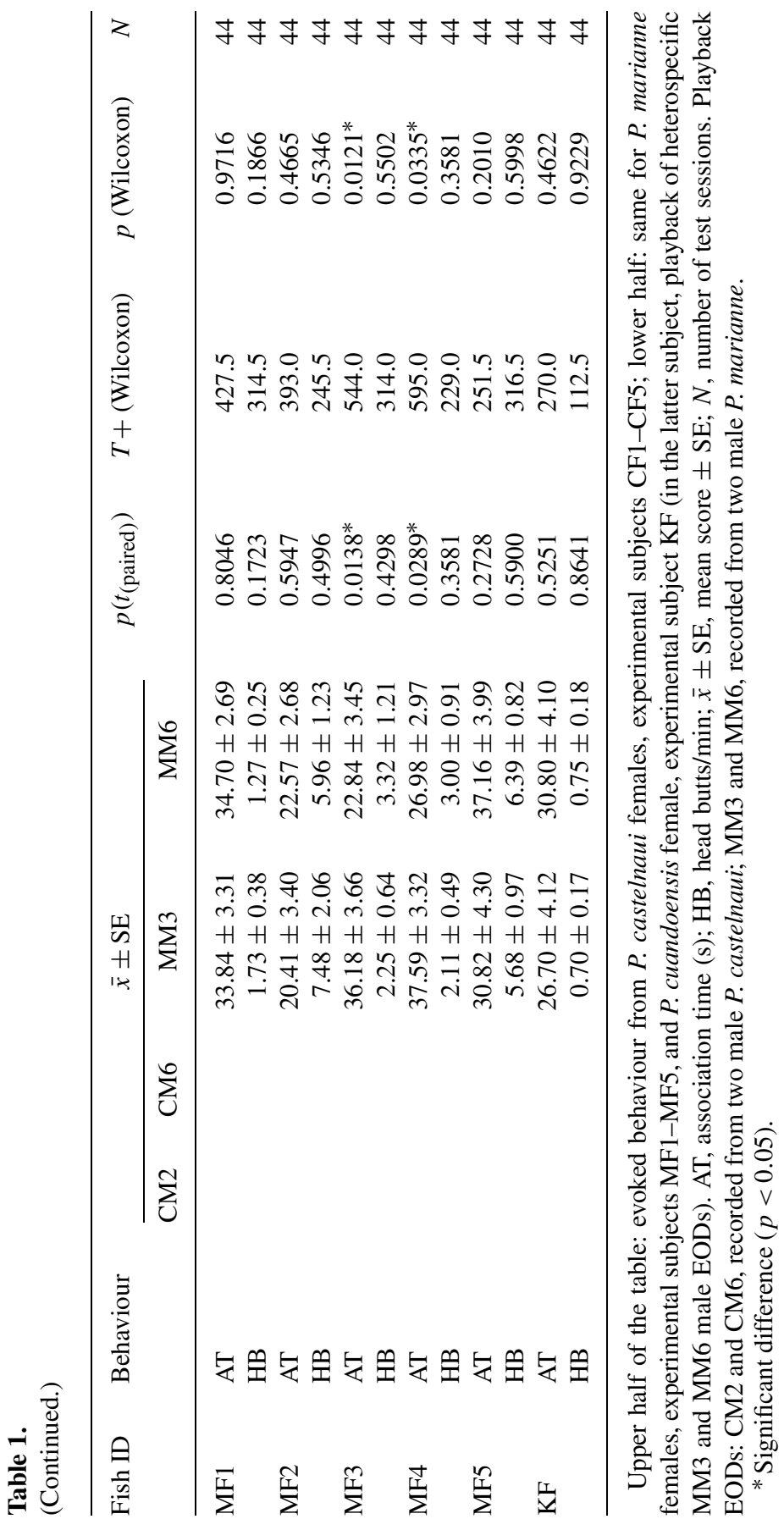



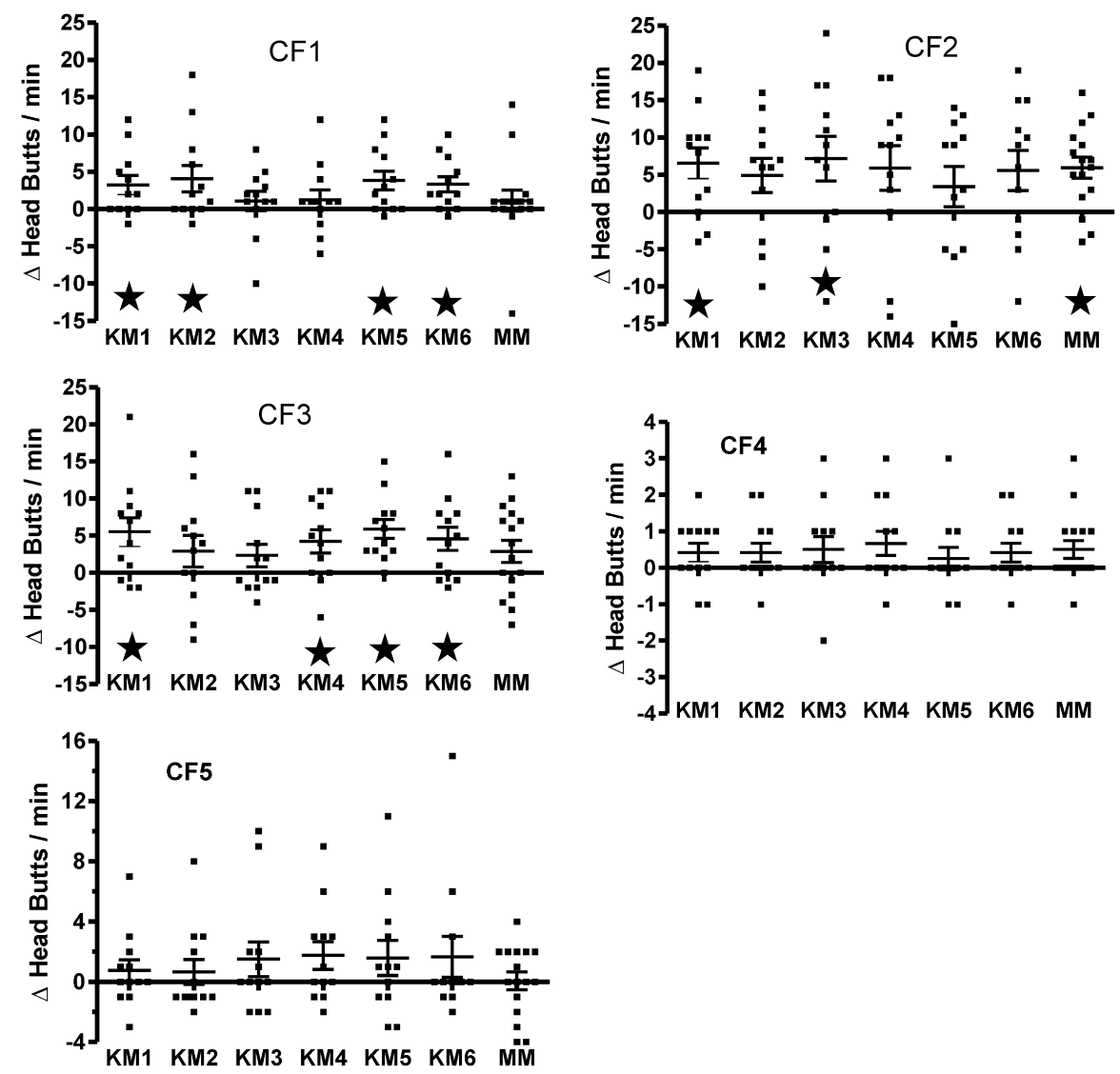

(A)

Figure 7. Mean difference scores \pm SE for (A) head butt frequency evoked in five female Pollimyrus castelnaui (CF1-CF5) by playback stimulation contrasting heterospecific male EODs with conspecific male EODs in a two-way simultaneous choice paradigm. Each heterospecific EOD was tested against a conspecific EOD separately. Each point is the result of an individual test. EOD stimulus pulse codes on abscissa: KM1-KM6, playback EODs recorded from six male P. cuandoensis; MM, playback EODs recorded from two P. marianne males, MM3 and MM6, scores combined. Ordinate: Frequency of head butts against active dipole stimulator, shown as the difference 'score for conspecific pulse minus heterospecific pulse' (scale magnified for CF4 and CF5). A positive difference shows more head butts to conspecific playback signal. Stars highlight scores significantly different from zero $(p<0.05)$. (B) Same for association time in s. (C) Same for circles per min.

longer times (association time). Subject MF1 showed relative avoidance to P. cuandoensis KM3 and -KM4 pulses, subject MF2 to KM5, subject MF4 to KM4, and subject MF5 avoided KM6 pulses (Figure 8B, Table 3). Sub- 

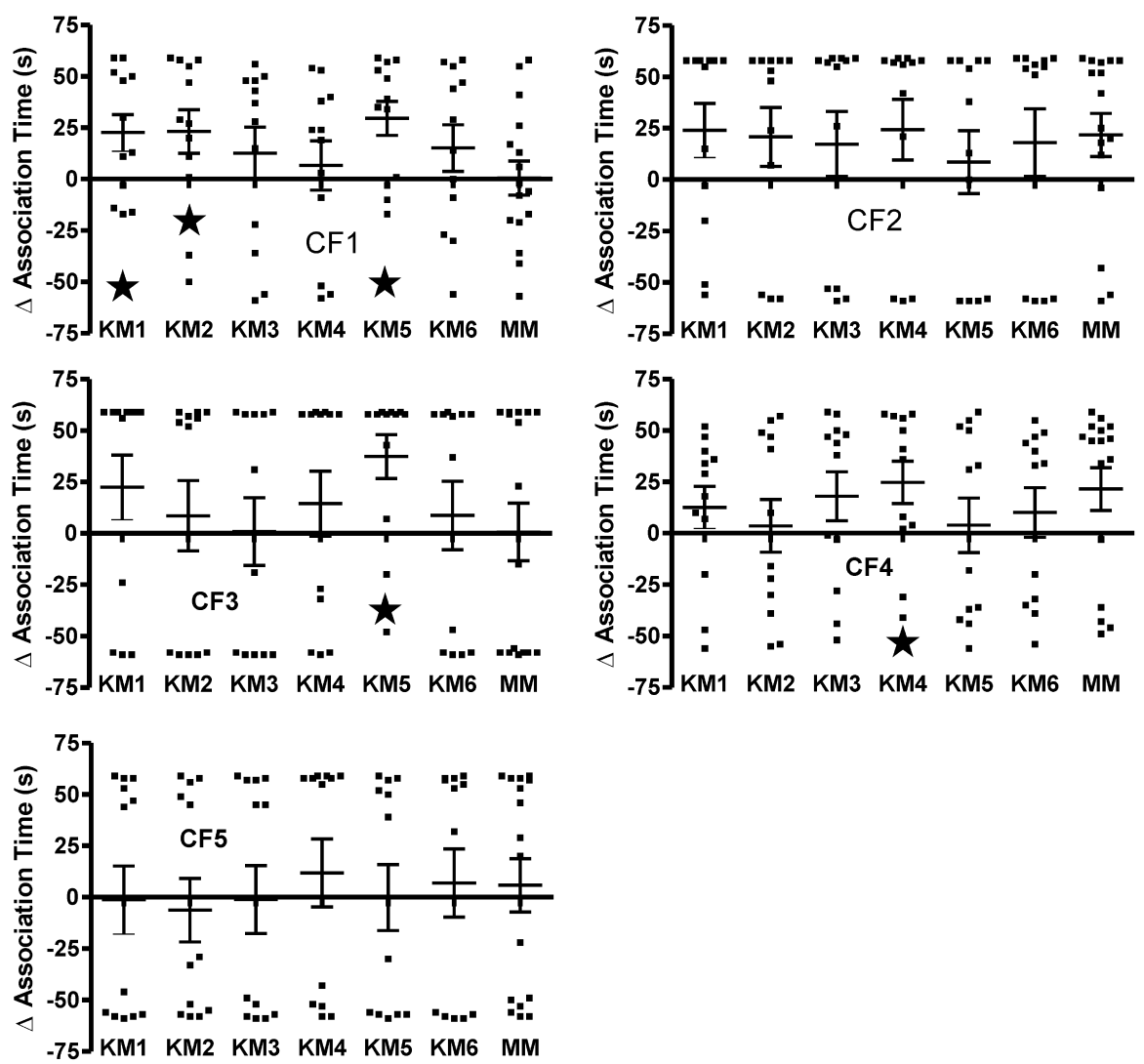

(B)

Figure 7. (Continued.)

ject MF3 narrowly missed passing the $p<0.05$ threshold in avoiding KM1 pulses (white star in Figure 8B).

Similar results were obtained in three experimental subjects which responded stronger to conspecific than heterospecific pulses in the frequency of Circling. Subject MF1 circled significantly less to a dipole playing back the $P$. cuandoensis KM2 EOD compared to its conspecific EOD. For subjects MF4 and MF5 the Pollimyrus cuandoensis EOD which proved less attractive than a conspecific EOD was KM6 (Figure 8C).

Generalising over all experimental $P$. marianne subjects and all tests in the three behaviours measured, the least attractive $P$. cuandoensis EOD proved to be pulse KM6 (relative avoidance significant in five test series), followed by KM5, KM3 and KM4 (two each), then KM1 and KM2 (one each). The 

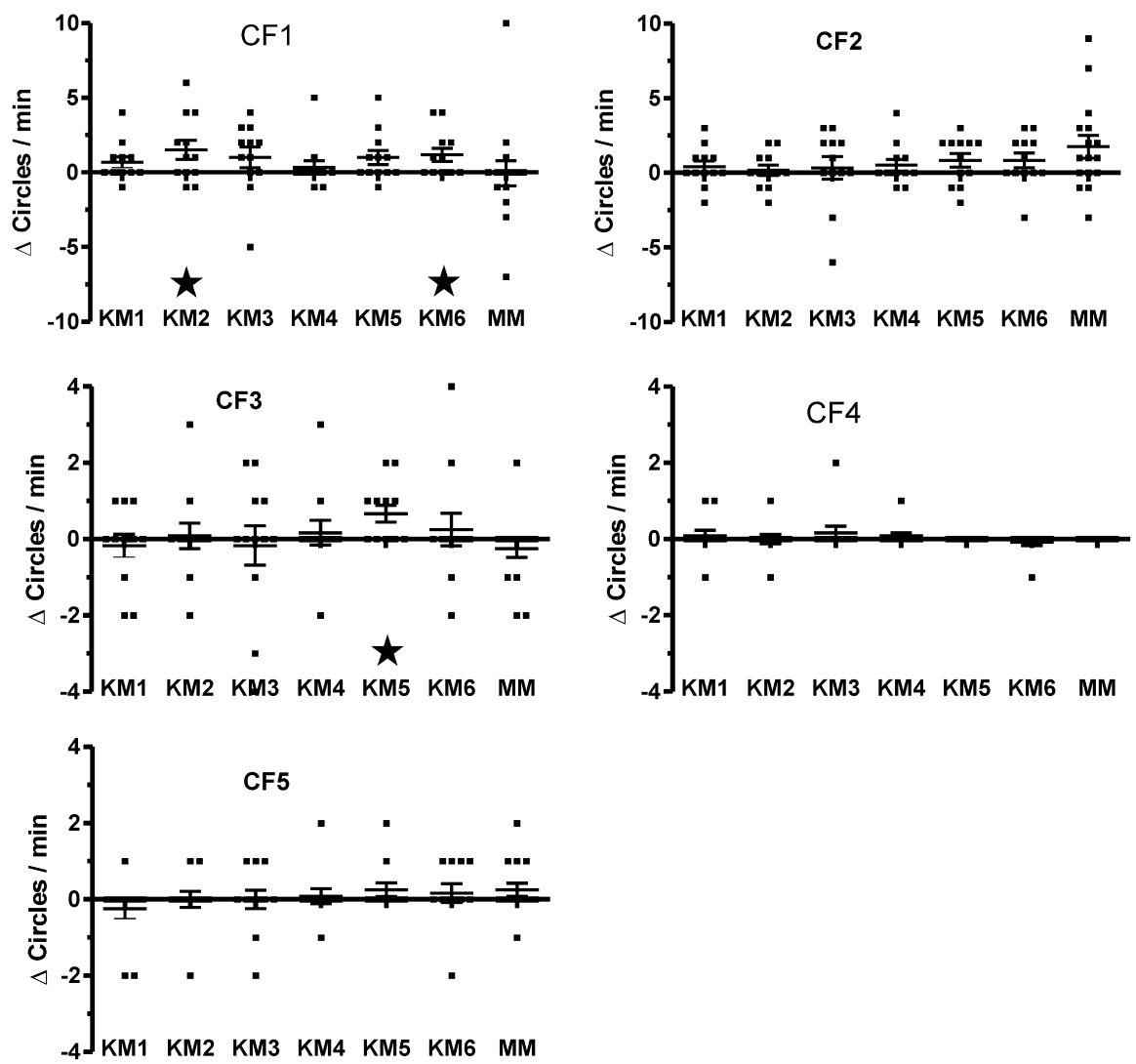

(C)

Figure 7. (Continued.)

P. castelnaui EOD pulse was neither discriminated against nor preferred by any of the subjects. On the whole, the five $P$. marianne experimental subjects discriminated considerably less often against heterospecific EODs (13 times) than did the P. castelnaui subjects (19 times out of 35 opportunities to do so), even though CF5 did not discriminate at all.

\subsubsection{Pollimyrus cuandoensis}

In the single $P$. cuandoensis female (KF) available the factor EOD pulse waveform had little effect on its choice of dipole stimulator when measured as head butts or association time (Figure 9, Table 3). The only significant choice observed was its weaker response to conspecific EOD waveform 
Table 2.

Head butt frequency, association time and circles/min evoked in five Pollimyrus castelnaui females (CF1-CF5) by playback of male EODs.

\begin{tabular}{llllll}
\hline Fish ID & $\begin{array}{l}\text { Con-/hetero- } \\
\text { specific EOD }\end{array}$ & $\Delta \bar{x} \pm \mathrm{SE}$ & $t_{\text {(paired) }}$ & $p_{\text {(two-tailed) }}$ & $N$ \\
& & & & \\
Head butts/min & & & & & \\
CF1 & CM/KM1 & $3.25 \pm 1.25$ & 2.600 & 0.0247 & 12 \\
CF1 & CM/KM2 & $4.08 \pm 1.76$ & 2.318 & 0.0410 & 12 \\
CF1 & CM/KM5 & $3.83 \pm 1.27$ & 3.016 & 0.0115 & 12 \\
CF1 & CM/KM6 & $3.33 \pm 1.01$ & 3.300 & 0.0071 & 12 \\
CF2 & CM/KM1 & $6.58 \pm 2.04$ & 3.225 & 0.0080 & 12 \\
CF2 & CM/KM3 & $7.17 \pm 2.97$ & 2.414 & 0.0344 & 12 \\
CF2 & CM/MM & $5.94 \pm 1.40$ & 4.243 & 0.0007 & 12 \\
CF3 & CM/KM1 & $5.50 \pm 1.92$ & 2.865 & 0.0154 & 12 \\
CF3 & CM/KM4 & $4.25 \pm 1.57$ & 2.707 & 0.0202 & 12 \\
CF3 & CM/KM5 & $5.92 \pm 1.26$ & 4.703 & 0.0006 & 12 \\
CF3 & CM/KM6 & $4.58 \pm 1.58$ & 2.904 & 0.0144 & 12 \\
Association time $(\mathrm{s})$ & & & & & \\
CF1 & CM/KM1 & $22.67 \pm 8.81$ & 2.573 & 0.0259 & 12 \\
CF1 & CM/KM2 & $23.17 \pm 10.65$ & 2.176 & 0.0522 & 12 \\
CF1 & CM/KM5 & $29.58 \pm 8.30$ & 3.562 & 0.0045 & 12 \\
CF3 & CM/KM5 & $37.42 \pm 10.68$ & 3.502 & 0.0049 & 12 \\
CF4 & CM/KM4 & $24.83 \pm 10.27$ & 2.419 & 0.0341 & 12 \\
Circles/min & & & & & \\
CF1 & CM/KM2 & $1.50 \pm 0.63$ & 2.367 & 0.0373 & 12 \\
CF1 & CM/KM6 & $1.18 \pm 0.44$ & 2.646 & 0.0228 & 12 \\
CF3 & CM/KM5 & $0.67 \pm 0.22$ & 2.966 & 0.0128 & 12 \\
\hline
\end{tabular}

In an individual test, one conspecific EOD was contrasted with one heterospecific EOD at a time in a two-way unforced choice paradigm. The mean difference 'conspecific score minus heterospecific score' is shown as $\Delta \bar{x} \pm$ SE. Positive scores indicate preference of conspecific EOD when compared to a heterospecific EOD, as indicated. Playback EODs used: KM1KM6, EODs recorded from six male P. cuandoensis; CM, EODs CM2 and CM6 recorded from two P. castelnaui males (scores of which were combined); MM, EODs MM3 and MM6 recorded from two $P$. marianne males (scores of which were combined). $N$, number of test sessions. Pulse pairings shown only when difference significant $(p<0.05)$, or only slightly greater (in italics). Therefore, there is no entry for subject CF5.

KM6 in comparison to $P$. marianne's EODs, as measured by the frequency of circling (paired $t$-test, $t_{11}=2.461, p=0.0316$; Wilcoxon $T^{+}=49$, $p=0.0137)$. 


\section{Table 3.}

Head butt frequency, association time and circles/min evoked in five Pollimyrus marianne females (MF1-MF5) and one P. cuandoensis female (KF) by playback of male EODs.

\begin{tabular}{llllll}
\hline Fish ID & $\begin{array}{c}\text { Con-/hetero- } \\
\text { specific EOD }\end{array}$ & $\Delta \bar{x} \pm \mathrm{SE}$ & $t_{\text {(paired) }}$ & $p_{\text {(two-tailed) }}$ & $N$ \\
& & & & & \\
Head butts/min & & & & & \\
MF1 & MM/KM3 & $1.92 \pm 0.51$ & 3.727 & 0.0033 & 12 \\
MF2 & MM/KM5 & $8.08 \pm 3.01$ & 2.687 & 0.0212 & 12 \\
MF4 & MM/KM6 & $2.25 \pm 0.72$ & 3.129 & 0.0960 & 12 \\
MF5 & MM/KM6 & $7.92 \pm 1.89$ & 4.183 & 0.0015 & 12 \\
Association time (s) & & & & & \\
MF1 & MM/KM3 & $32.25 \pm 6.95$ & 4.643 & 0.0007 & 12 \\
MF1 & MM/KM4 & $28.08 \pm 11.26$ & 2.495 & 0.0298 & 12 \\
MF2 & MM/KM5 & $23.33 \pm 7.96$ & 2.932 & 0.0136 & 12 \\
MF3 & MM/KM1 & $27.25 \pm 12.58$ & 2.167 & 0.0531 & 12 \\
MF4 & MM/KM4 & $27.33 \pm 7.19$ & 3.800 & 0.0029 & 12 \\
MF5 & MM/KM6 & $39.17 \pm 12.13$ & 3.228 & 0.0080 & 12 \\
Circles/min & & & & & \\
MF1 & MM/KM2 & $1.17 \pm 0.42$ & 2.755 & 0.0187 & 12 \\
MF4 & MM/KM6 & $0.75 \pm 0.28$ & 2.691 & 0.0210 & 12 \\
MF5 & MM/KM6 & $3.50 \pm 1.23$ & 2.836 & 0.0162 & 12 \\
KF & KM6/CM & $-1.17 \pm 0.47$ & 2.461 & 0.0316 & 12 \\
\hline
\end{tabular}

In an individual test, conspecific EODs were contrasted with one heterospecific EOD at a time in a two-way unforced choice paradigm. The mean difference 'conspecific score minus heterospecific score' is shown as $\Delta \bar{x} \pm$ SE. Positive scores indicate preference of conspecific EOD. Playback EODs used: KM1-KM6, EODs recorded from six male $P$. cuandoensis; MM, EODs MM3 and MM6 recorded from two P. marianne males (scores of which were combined); CM, EODs CM2 and CM6 recorded from two P. castelnaui males (scores of which were combined). $N$, number of test sessions. Pulse pairings shown only when difference significant ( $p<0.05$ or close to 0.05 , in italics).

\section{Discussion}

Experimental Pollimyrus castelnaui females (a species inhabiting the Okavango) and $P$. marianne females (inhabiting the Zambezi) both showed a strong tendency to associate with signal sources playing back conspecific male EODs rather than those of $P$. cuandoensis. Response differences were seen in association time, i.e., a measure of female choosiness, and head butts and circling, i.e., measures of female preference (as distinguished by Ronald et al., 2012). One $P$. castelnaui experimental female, although responding to the paired playback stimulation, did not respond differentially, whereas all 

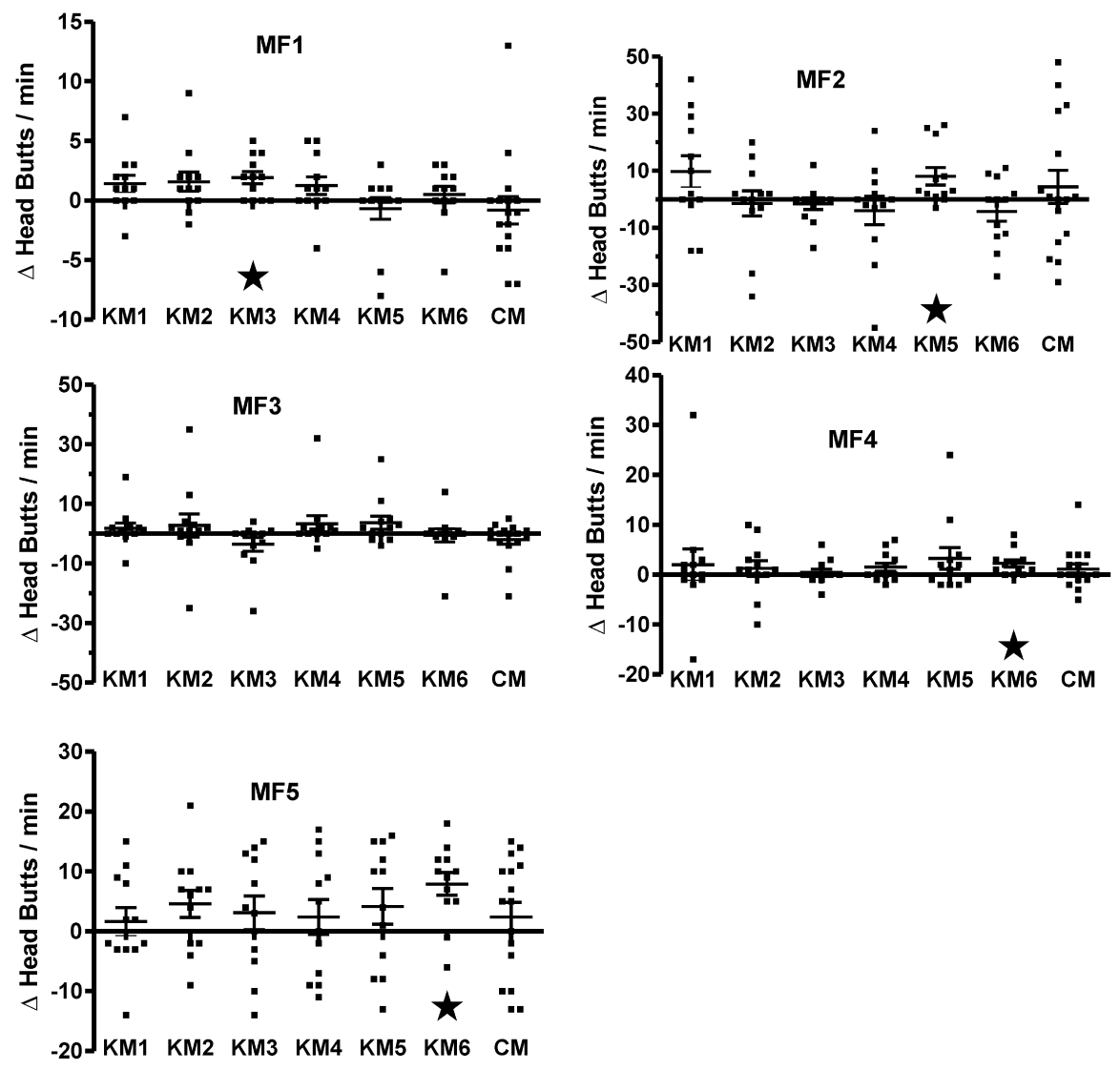

(A)

Figure 8. Mean difference scores \pm SE for (A) association time evoked in five female Pollimyrus marianne (MF1-MF5) by playback stimulation contrasting heterospecific male EODs with conspecific male EODs in a two-way simultaneous choice paradigm. One heterospecific EOD at a time was tested against one conspecific EOD. Each point is the result of an individual test. EOD stimulus pulse codes on abscissa: KM1-KM6, playback EODs recorded from six male $P$. cuandoensis; CM, playback EODs recorded from two $P$. castelnaui males, CM2 and CM6, scores combined. Ordinate: Association time with active dipole stimulator, shown as the difference 'score for conspecific pulse minus heterospecific pulse'. Positive scores indicate preference for conspecific playback EOD. Black stars highlight scores significantly different from zero $(p<0.05)$; white star, narrowly missing significance in panel B. (B) Same for association time in s. (C) Same for circles per min.

other experimental subjects, including those of the other two species, did at least in one paired test series per experimental female. The acoustic, tactile and olfactory stimuli from a live courting male (Lamml \& Kramer, 2005, 

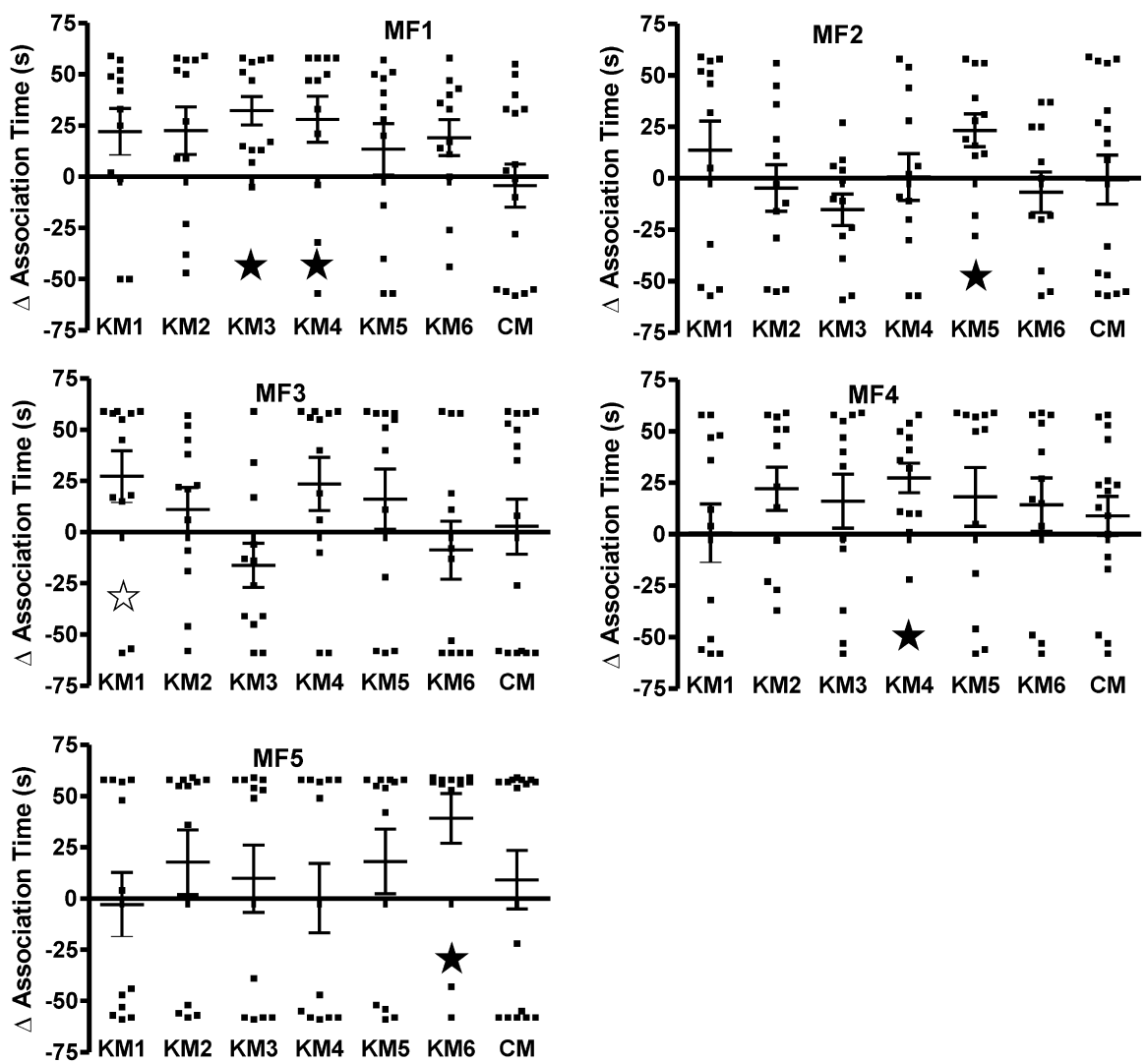

(B)

Figure 8. (Continued.)

2006; Baier \& Kramer, 2007) in a more natural setting were, of course, excluded in this laboratory study that focussed on the EOD as a putative sensory basis for assortative mating. Common developmental and conditional factors are also seen as sources for individual differences in female mate choice, and variation in both response readiness and in female sensory detection of male displays is suggested to depend on factors such as nutrient availability, hormone profiles or age (Ronald et al., 2012).

The present study shows that sexual selection in the form of female choice is a factor in maintaining the three-sibling species complex of the Upper Zambezi-Kwando-Okavango system that is inter-linked by tenuous channels at times of flood in the Upper Zambezi and Okavango rivers. Hybridization of both $P$. castelnaui and $P$. marianne females with $P$. cuandoensis males 

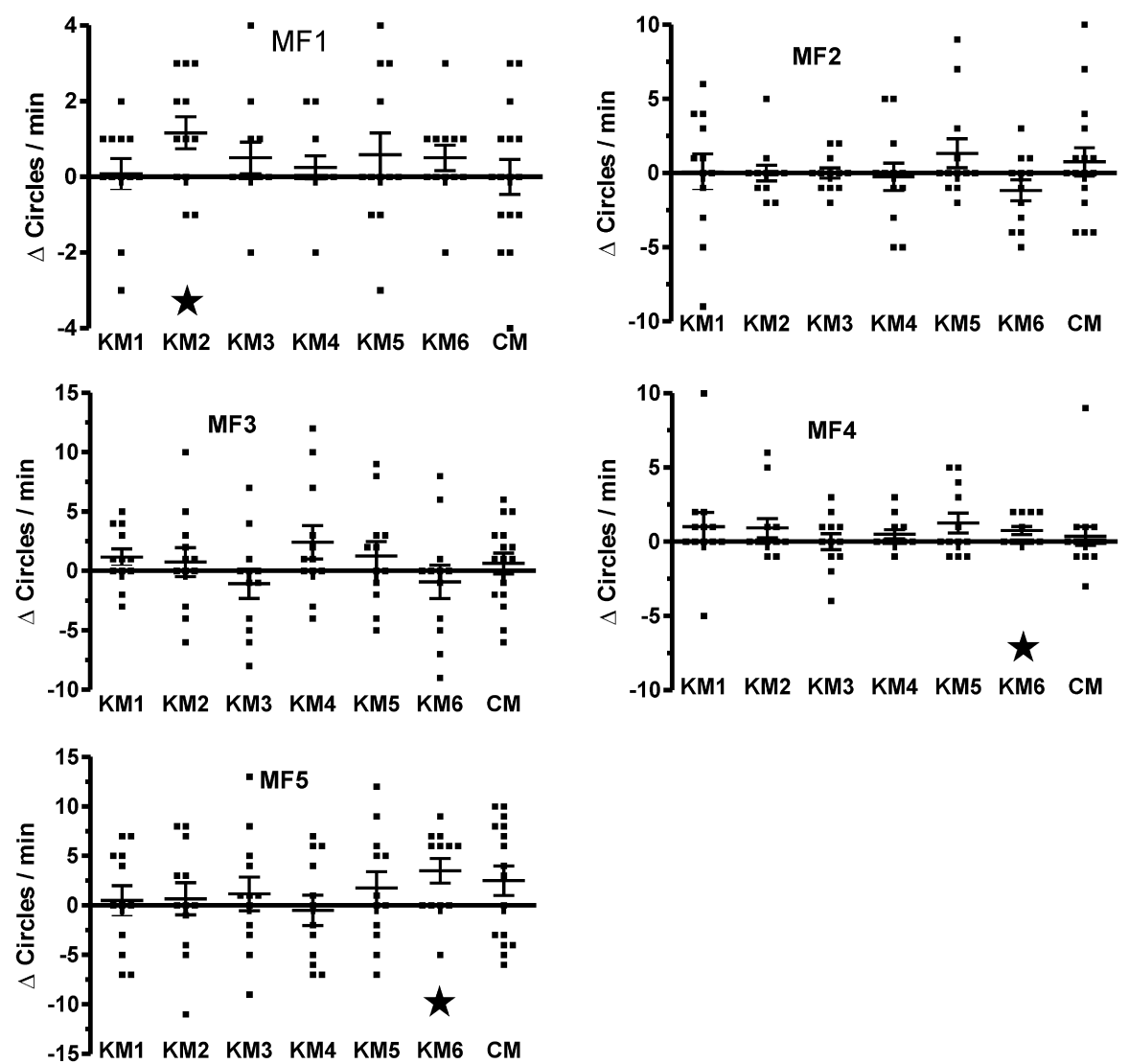

(C)

Figure 8. (Continued.)

seems to be strongly selected against in the Okavango and the Zambezi. In 35 test series, opportunities to choose between male playback EODs contrasting conspecific with heterospecific EODs, neither in P. castelnaui nor P. marianne was there a single incidence of a stronger response to heterospecific EODs - but clearly stronger responses to conspecific EODs in 19 and 13 test series, respectively. The experimental females of both $P$. castelnaui and $P$. marianne discriminated against the playback male EODs of their nearest neighbour, $P$. cuandoensis. In the present tests, $P$. castelnaui and $P$. marianne did not discriminate against each other's EODs, with one exception in $P$. castelnaui specimen CF2 observed in head butts. This seems to show that the rejection of $P$. cuandoensis EODs by the females of the two species in the 

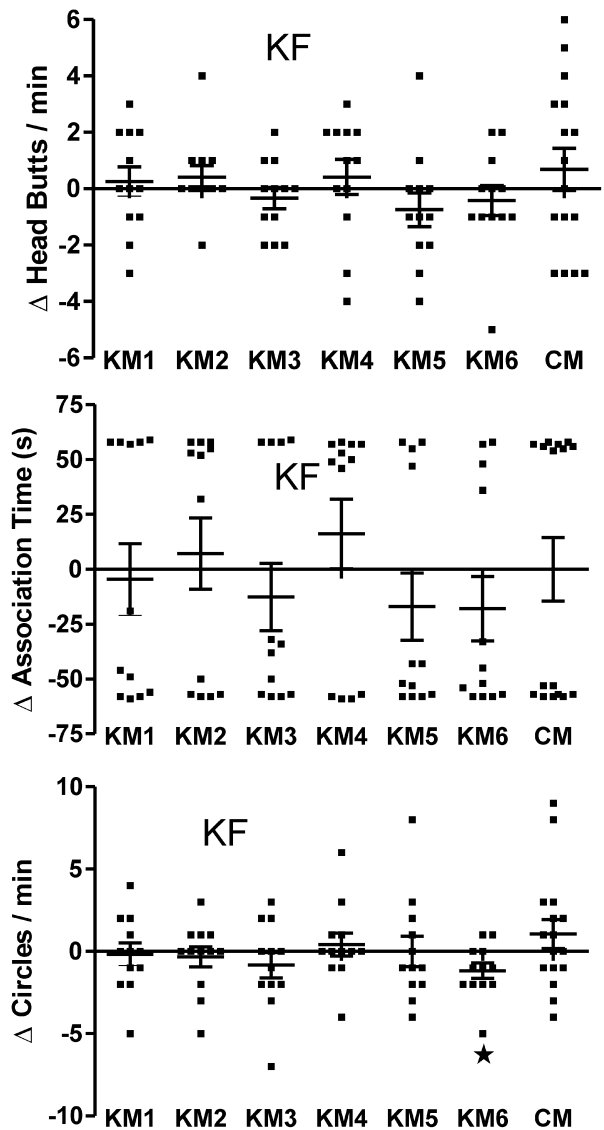

Figure 9. Mean difference scores $\pm \mathrm{SE}$ for behaviour evoked in female P. cuandoensis KF, by playback stimulation contrasting conspecific male EODs with heterospecific EODs in a two-way simultaneous choice paradigm. One $P$. marianne EOD at a time was tested against one out of 6 conspecific EODs (KM1-KM6) and a P. castelnaui EOD (CM). Each point is the result of an individual test. EOD stimulus pulse codes on abscissa: KM1-KM6, playback EODs recorded from six male $P$. cuandoensis; CM, playback EODs recorded from two $P$. castelnaui males, CM2 and CM6, scores combined. Ordinates: Head butts per min, displayed at active dipole stimulator (top panel), association time in s (middle panel) and circling per min (bottom panel), all shown as difference scores for 'conspecific EOD minus heterospecific EOD'. Negative scores indicate preference for heterospecific playback EOD, as indicated by a star $(p<0.05)$.

main systems on either side of the Kwando is an evolved one, one to exclude hybridisation between neighbours. The relative avoidance of $P$. cuandoensis' EODs was, however, more pronounced in $P$. castelnaui than $P$. marianne. 
The rejection of $P$. cuandoensis EODs by $P$. castelnaui and $P$. marianne females seems to effectively block panmixy in the Okavango and the Zambezi, but not so in the Kwando. Pollimyrus cuandoensis females do not seem to resist courting males of the other two species invading the Kwando at times of the major rivers in flood. The P. cuandoensis female KF even preferred $P$. marianne's EOD over one of its own species, KM6, that was quite similar to its own EOD (Figure 2). Assuming P. cuandoensis female KF was representative in not discriminating against the other two Pollimyrus species' EODs, this seems to show that in $P$. cuandoensis females, closely related to $P$. marianne as they are, no resistance to at least the $P$. marianne EOD has yet evolved. This idea is supported by the lack of differentiation in the cyt- $b$ gene between the two species (Kramer et al., 2003, 2013). Whereas P. castelnaui and $P$. marianne clades must have separated 3.8-7.6 million years ago, those of $P$. marianne and $P$. cuandoensis are estimated to have separated about 2.1 million years ago (assuming a molecular clock of $0.58 \%$ distance equals 1 million years; obtained for freshwater fish, Burridge et al., 2008). The maternal cyt- $b$ evidence shows that $P$. cuandoensis originated by unidirectional hybridization, with $P$. marianne the 'mother species' (as termed by Wirtz, 1999).

How could assortative mating have evolved in P. castelnaui and P. marianne females? The artificial neural network model by Haas \& Brodin (2006) shows that learning by imprinting on a parent signal that is used in the communication between the sexes could have initiated a disruptive selection process in parapatry or even sympatry. A pure, i.e., stereotyped and stable parent signal on the population level, such as a clean black coat in the carrion crow vs a grey one with specific black areas in the hooded crow, the two vicariant varieties of a European crow (Corvus corone), was easily recognised and correctly classified by the model after learning, compared to a shaggy and variable grey-black coat as shown by hybrid birds from the narrow contact zone (hybridization zone). Brodin \& Haas (2006) suggest additional selection processes could reinforce the preference for conspecific signals (non-shaggy signals) to become eventually genetically based.

Sexual imprinting based on visual and/or olfactory cues has been shown in young experimental females of two pairs of sibling species of cichlid fish that developed a preference for the males of their foster mother's species (Verzijden and ten Cate, 2007; Verzijden et al., 2008). Other forms of imprinting (filial/social/rival/orientational) in the young ones of various groups of fish 
are also reviewed in Gómez-Laplaza \& Gil-Carnicero (2008) and Verzijden et al. (2008). In fry of the present Pollimyrus species, learning by imprinting on the father fish's EOD waveform is conceivable. After the last spawning bout when the female has left the area for good, the father fish collects the eggs and tends the nest from egg stage until the juveniles disband (Lamml \& Kramer, 2005; Baier \& Kramer, 2007). This is assumed to occur when the juveniles start to behave aggressively against each other, as has been observed at an age of 50-60 days in P. adspersus (Postner \& Kramer, 1995; Kramer \& Postner, 1997). At that age the larval discharge of the fry is beginning to be replaced by the adult discharge that is rapidly increasing in strength (Westby \& Kirschbaum, 1978), as has also been observed in P. castelnaui and P. marianne, although at a somewhat earlier age (Baier et al., 2006). There is thus ample opportunity for the fry to learn the father's EOD waveform. Adult mormyrids, the brainiest among all fish (Meek \& Nieuwenhuys, 1998), have proven excellent learners in many studies of this laboratory (Kramer, 2009).

Under these conditions, how could P. cuandoensis have originated as a hybrid species? The basal clade in the present trio of species is $P$. castelnaui (Kramer et al., 2003). After P. marianne had differentiated from P. castelnaui in the Upper Zambezi, specimens of P. marianne that were swept into the Kwando by the Zambezi in flood represented the rarer species in the Kwando. Following the theory of Wirtz (1999), unidirectional hybridization occurs when females, that is, the more discriminating sex, of the rare species resist courting males of the more common species, but cannot find a mate of their own species. Eventually, the discriminating P. marianne females accepted the males of the common species as mates, and the hybrid offspring all carried their mothers' cyt- $b$ gene. Pollimyrus cuandoensis has thus originated as a phenotypically intermediate hybrid species, with $P$. marianne as the 'mother species' and P. castelnaui as the 'father species' (Wirtz, 1999). In many freshwater fish unidirectional hybridization has occurred whenever a translocated female, representing the rarer species, could not find a mate of its own species so that she eventually accepted an alien male as a mate (Wirtz, 1999). This situation may be fairly common in the Kwando at times of the Zambezi and Okavango in flood. Still ongoing hybridization in spite of species differentiation may be the reason for the 'shaggy' (Brodin \& Haas, 2006), i.e., variable EOD waveforms of $P$. cuandoensis on the population level. 
Hybridization in a species pair can result in speciation reversal even in three or more related species, e.g., when an invading or an introduced freshwater fish species crosses with a native species, initiating gene exchange between genetically isolated native species by forming a genetic 'bridge' (McDonald et al., 2008). Species reversal by hybridization in sympatric whitefish species flocks and phenotypic intermediacy, as well as reduction of phenotypic variability has been observed in eutrophic lakes where feeding and spawning niches were reduced by anthropogenic pollution (Vonlanthen et al., 2012). We conclude that past and probably ongoing hybridization in the Kwando has not been able to drive the Okavango nor the Upper Zambezi 'parent' species of $P$. cuandoensis, $P$. castelnaui and $P$. marianne, out of existence in their native rivers. Choosy females of the latter two species rejecting the advertisement signals (EODs) of $P$. cuandoensis males keep up the trio of sibling species by assortative mating.

\section{Acknowledgements}

We wish to thank the governments of Namibia and Botswana for permits, and F.H. van der Bank (whose research was partially funded by the National Research Foundation, South Africa) and the late J.S. Engelbrecht for helping to sample specimens of the three species. Peter Machnik helped with certain recordings, the manipulation of electronic equipment and reading the manuscript, and Ellen Fröhlich with computer know-how and photographic work. This study was supported by Deutsche Forschungsgemeinschaft (DFG) grants KR 446/12 and previous grants.

\section{References}

Andersson, M. (1994). Sexual selection. - Princeton University Press, Princeton, NJ.

Andersson, M. \& Simmons, L.W. (2006). Sexual selection and mate choice. - Trends Ecol. Evol. 21: 296-302.

Arnegard, M.E., Bogdanowicz, S.M. \& Hopkins, C.D. (2005). Multiple cases of striking genetic similarity between alternate electric fish signal morphs in sympatry. - Evolution 59: 324-343.

Arnegard, M.E., Jackson, B.S. \& Hopkins, C.D. (2006). Time-domain signal divergence and discrimination without receptor modification in sympatric morphs of electric fishes. J. Exp. Biol. 209: 2182-2198.

Arnegard, M.E., McIntyre, P.B., Harmon, L.J., Zelditch, M.L., Crampton, W.G.R., Davis, J.K., Sullivan, J.P., Lavoué, S. \& Hopkins, C.D. (2010). Sexual signal evolution outpaces ecological divergence during electric fish species radiation. - Am. Nat. 176: 335-356. 
Baier, B. \& Kramer, B. (2007). Electric communication in the courtship and spawning of two sibling species of dwarf stonebasher from southern Africa, Pollimyrus castelnaui and P. marianne (Mormyridae, Teleostei): evidence for a non species-specific communication code? - Behaviour 144: 115-142.

Baier, B., Lamml, M. \& Kramer, B. (2006). Ontogeny of the electric organ discharge in two parapatric species of the dwarf stonebasher, Pollimyrus castelnaui and P. marianne (Mormyridae, Teleostei). — Acta Zool. 87: 209-214.

Bennett, M.V.L. (1971a). Electric organs. — In: Fish physiology (Hoar, W.S. \& Randall, D.J., eds). Academic Press, London, p. 347-491.

Bennett, M.V.L. (1971b). Electroreception. — In: Fish physiology (Hoar, W.S. \& Randall, D.J., eds). Academic Press, London, p. 493-574.

Brodin, A. \& Haas, F. (2006). Speciation by perception. — Anim. Behav. 72: 139-146.

Bullock, T.H., Hopkins, C.D., Popper, A.N. \& Fay, R.R. (2005). Electroreception. Springer, New York, NY.

Burridge, C.P., Craw, D., Fletcher, D. \& Waters, J.M. (2008). Geological dates and molecular rates: fish DNA sheds light on time dependency. - Mol. Biol. Evol. 25: 624-633.

Cochran, W.G. \& Cox, G.M. (1957). Experimental designs, 2nd edn. - Wiley, New York, NY.

Gallant, J.R., Arnegard, M.E., Sullivan, J.P., Carlson, B.A. \& Hopkins, C.D. (2011). Signal variation and its morphological correlates in Paramormyrops kingsleyae provide insight into the evolution of electrogenic signal diversity in mormyrid electric fish. - J. Comp. Physiol. A 197: 799-817.

Gómez-Laplaza, L.M. \& Gil-Carnicero, P. (2008). Imprinting in fish: a little explored phenomenon with possible implications for fish welfare. - Annu. Rev. Biomed. Sci. 10: T51-T62.

Graff, C. \& Kramer, B. (1992). Trained weakly-electric fishes Pollimyrus isidori and Gnathonemus petersii (Mormyridae, Teleostei) discriminate between waveforms of electric pulse discharges. — Ethology 90: 279-292.

Hanika, S. \& Kramer, B. (2005). Intra-male variability of its communication signal in the weakly electric fish, Marcusenius macrolepidotus (South African form), and possible functions. - Behaviour 142: 145-166.

Hanika, S. \& Kramer, B. (2008). Plasticity of electric organ discharge waveform in the South African bulldog fish, Marcusenius pongolensis: tradeoff between male attractiveness and predator avoidance? - Front. Zool. 5: 7.

Hopkins, C.D. (2009). Electrical perception and communication. - In: Encyclopedia of neuroscience (Squire, L.R., ed.). Academic Press, Oxford, p. 813-831.

Kramer, B. (1990). Electrocommunication in teleost fishes: behavior and experiments. Springer, Berlin.

Kramer, B. (1996). Electroreception and communication in fishes. - Gustav Fischer, Stuttgart.

Kramer, B. (2009). Electric communication and electrolocation. - In: Encyclopedia of neuroscience (Binder, M.D., Hirokawa, N. \& Windhorst, U., eds). Springer, Berlin, p. 10381045. 
Kramer, B. \& Kuhn, B. (1990). Species recognition by the sequence of discharge intervals in weakly electric fishes of the genus Campylomormyrus (Mormyridae, Teleostei). - Anim. Behav. 48: 435-445.

Kramer, B. \& Lücker, H. (1990). Species recognition by EOD interval pattern. - In: Electrocommunication in teleost fishes: behavior and experiments (Kramer, B., ed.). Springer, Berlin, p. 157-170.

Kramer, B. \& Postner, M. (1997). Development of electrical signalling in larvae of the African fish, Pollimyrus adspersus (Mormyridae, Teleostei): the patterns of interdischarge intervals. - J. Zool. (Lond.) 243: 329-340.

Kramer, B., van der Bank, H., Flint, N., Sauer-Gürth, H. \& Wink, M. (2003). Evidence for parapatric speciation in the Mormyrid fish, Pollimyrus castelnaui (Boulenger, 1911), from the Okavango-Upper Zambezi River systems: P. marianne sp. nov., defined by electric organ discharges, morphology and genetics. — Environ. Biol. Fish. 67: 47-70.

Kramer, B., van der Bank, F.H. \& Wink, M. (2013). Marked differentiation in a new species of dwarf stonebasher, Pollimyrus cuandoensis sp. nov. (Mormyridae, Teleostei), from a contact zone with two sibling species of the Okavango and Zambezi rivers. - J. Nat. Hist. 48: 429-463.

Kramer, B. \& Weymann, D. (1987). A microprocessor system for the digital synthesis of pulsed or continuous discharges of electric fish (or animal vocalizations). — Behav. Brain Res. 23: 167-174.

Kroodsma, D.E. (1989). Suggested experimental designs for song playback. — Anim. Behav. 37: 600-609.

Lamml, M. \& Kramer, B. (2005). Sound production in the reproductive behaviour of the weakly electric fish Pollimyrus marianne Kramer et al. 2003 (Mormyridae, Teleostei). Bioacoustics 15: 51-78.

Lamml, M. \& Kramer, B. (2006). Differentiation of courtship songs in parapatric sibling species of dwarf stonebashers from southern Africa (Mormyridae, Teleostei). - Behaviour 143: 783-810.

Lissmann, H.W. (1958). On the function and evolution of electric organs in fish. - J. Exp. Biol. 35: 156-191.

Machnik, P. \& Kramer, B. (2008a). Female choice by electric pulse duration: attractiveness of the males' communication signal assessed by female bulldog fish, Marcusenius pongolensis (Mormyridae, Teleostei). — J. Exp. Biol. 211: 1969-1977.

Machnik, P. \& Kramer, B. (2008b). A male's playback signal turns female Marcusenius pongolensis receivers on or off depending on his behavioural state. - Commun. Integr. Biol. 1: 128-131.

Machnik, P. \& Kramer, B. (2011). Novel electrosensory advertising during diurnal resting period in male snoutfish, Marcusenius altisambesi (Mormyridae, Teleostei). — J. Ethol. 29: 131-142.

Machnik, P., Markowski, B. \& Kramer, B. (2010). Intra- versus intersexual selection in the dimorphic electric organ discharges of the snoutfish Marcusenius altisambesi (Mormyriformes, Teleostei). - Behaviour 147: 677-704. 
Markowski, B., Baier, B. \& Kramer, B. (2008). Differentiation in electrical pulse waveforms in a pair of sibling Dwarf Stonebashers, Pollimyrus castelnaui and P. marianne: possible mechanisms and functions (Mormyridae, Teleostei). - Behaviour 145: 115-135.

McDonald, D.B., Parchman, T.L., Bower, M.R., Hubert, W.A. \& Rahel, F.J. (2008). An introduced and a native vertebrate hybridize to form a genetic bridge to a second native species. - Proc. Natl. Acad. Sci. USA 105: 10837-10842.

Meek, J. \& Nieuwenhuys, R. (1998). (The brains of) holosteans and teleosts. - In: The central nervous system of vertebrates (Nieuwenhuys, R., ten Donkelaar, H.J. \& Nicholson, C., eds). Springer, New York, NY, p. 759-937.

Moller, P. (1995). Electric fishes: history and behaviour. - Chapman \& Hall, London.

Paintner, S. \& Kramer, B. (2003). Electrosensory basis for individual recognition in a weakly electric, mormyrid fish, Pollimyrus adspersus (Günther, 1866). — Behav. Ecol. Sociobiol. 55: 197-208.

Postner, M. \& Kramer, B. (1995). Electrosensory thresholds in larvae of the weakly electric fish Pollimyrus isidori (Mormyridae, Teleostei) during ontogeny. - J. Exp. Biol. 198: 783-791.

Ronald, K.L., Fernàndez-Juricic, E. \& Lucas, J. (2012). Taking the sensory approach: how individual differences in sensory perception can influence mate choice. - Anim. Behav. 84: 1283-1294.

Szabo, T. (1974). Anatomy of the specialized lateral line organs of electroreception. - In: Handbook of sensory physiology (Fessard, A., ed.). Springer, Berlin, p. 13-58.

Szabo, T. \& Fessard, A. (1974). Physiology of electroreceptors. — In: Handbook of sensory physiology (Fessard, A., ed.). Springer, Berlin, p. 59-124.

Verzijden, M.N. \& ten Cate, C. (2007). Early learning influences species assortative mating preferences in Lake Victoria cichlid fish. — Biol. Lett. 3: 134-136.

Verzijden, M.N., Korthof, R.E.M. \& ten Cate, C. (2008). Females learn from mothers and males learn from others. The effect of mother and siblings on the development of female mate preferences and male aggression biases in Lake Victoria cichlids, genus Mbipia. Behav. Ecol. Sociobiol. 62: 1359-1368.

Vonlanthen, P., Bittner, D., Hudson, A.G., Young, K.A., Müller, R., Lundsgaard-Hansen, B., Roy, D., Di Piazza, S., Largiader, C.R. \& Seehausen, O. (2012). Eutrophication causes speciation reversal in whitefish adaptive radiations. — Nature 482: 357-362.

Westby, G.W.M. \& Kirschbaum, F. (1978). Emergence and development of the electric organ discharge in the mormyrid fish, Pollimyrus isidori. II. Replacement of the larval by the adult discharge. - J. Comp. Physiol. A 127: 45-59.

Wirtz, P. (1999). Mother species-father species: unidirectional hybridization in animals with female choice. - Anim. Behav. 58: 1-12. 